\title{
NUMERICAL STUDY OF MHD BOUNDARY LAYER STAGNATION POINT FLOW AND HEAT TRANSFER OVER AN EXPONENTIALLY STRETCHING SURFACE WITH THERMAL RADIATION
}

\author{
M.S.Abel ${ }^{1}$, Prashant G Metri ${ }^{2}$, Veena.M.Basangouda ${ }^{3}$, M.Narayana ${ }^{4}$ \\ ${ }^{1}$ Dept of Mathematics Gulbarga University, Gulbarga-585106, Karnataka, India \\ ${ }^{2}$ Dept of Mathematics Gulbarga University, Gulbarga-585106, Karnataka, India \\ ${ }^{3}$ Dept of Mathematics Gulbarga University, Gulbarga-585106, Karnataka, India \\ ${ }^{4}$ School of Advanced science, VIT University, Vellore 632014.Tamilnadu, India
}

\begin{abstract}
An analysis has been carried out to Numerical study of MHD boundary layer stagnation point flow and heat transfer over an exponentially stretching surface with thermal radiation. The coupled partial differential equations are reduced into ordinary differential equations by similarity transformations. Numerical solutions of the coupled non-linear system is obtained by using shooting technique namely known as Runge-Kutta method. The convergence salient features of the flow and heat transfer characteristics are analyzed and discussed in detail through graphs. The variation of pradntl number, Grashoff number, Eckert number are discussed in detail, comparison of the present results with known numerical results of stagnation point flow and thermal radiation is made excellent agreement is noted. Applications are used in engineering process such as extraction of polymer sheet, paper production, glass fiber production and chemical engineering systems.
\end{abstract}

Keywords: Boundary layer flow, exponentially stretching sheet, Numerical solution, Thermal Radiation. ***

\section{INTRODUCTION:}

The study of flow over a stretching sheet has generated much interested in recent years in view of its numerous industrial applications such as the aerodynamic extrusion of plastic sheets, the boundary layer ,condensation process of metallic plate in cooling bath and glass, and also in polymer industries. The boundary layer flow over a stretching sheet was first studied by Sakiadis [4]. Later, Crane [8] extended this idea for the two dimensional flow over a stretching sheet problem. Gupta and Gupta [12], Carragher and Crane [11], Dutta et al. [5] studied the heat transfer in the flow over a stretching surface taking into account different aspects of the problem. Magyari and Keller [7] investigated the study of boundary layers on an exponentially stretching continuous surface with an exponential temperature distribution. Aboeldahab and Gendy [6] studied the radiation effects on MHD free convective flow of a gas past a semi-infinite vsrtical plate with variable thermo physical properties for higher-temperature difference. Many other problems on exponentially stretching surface were discussed by Raptis et al. [2], Partha et al. [9] and Sajid and Hayat [10]. Jat and Chaudhary [13-16] studied the MHD boundary layer flow over a stretching sheet for stagnation point, heat transfer with and without viscous dissipation and Joule heating. Bidin and Nazar [3] investigated the Numerical solution of the boundary layer flow over an exponentially stretching sheet with thermal radiation. Recently Ishak [1] investigated the thermal radiation effects on hydromagnetic flow due to an exponentially stretching sheet. Realizing the increasing technical applications of MHD effects, the present paper studies the problem of MHD boundary layer flow over an exponentially stretching sheet with viscous dissipation and radiation effects. Cortell(19),Xu and Liao.Hayat at al.and Hayat and SajidElbashbeshy added new dimension to the study of exponentially continuous stretching surface.

The studies of thermal radiation and heat transfer are important in electrical power generation, astrophysical flows ,solar power technology and other industries areas. A lot of extensive literature that deals with flows in the presence of radiation effects is now available. Elbashbeshy and Dimian analyzed boundary layer flow in presence of radiation effect and heat transfer over the wedge with viscous coefficient. Cortell has been solved a problem on the effect of radiation on Blasius flow by using Runge-Kutta fourth order approach.

In this paper, we investigate numerically the effect of thermal radiation on two dimensional boundary layer flow and heat transfer over an exponentially stretching sheet, which has been solved by numerically .By applying similarity transformation, the boundary layer equations are solved by numerically using Runge-Kutta method(Cortell 25). 


\section{FORMULATION OF THE PROBLEM.}

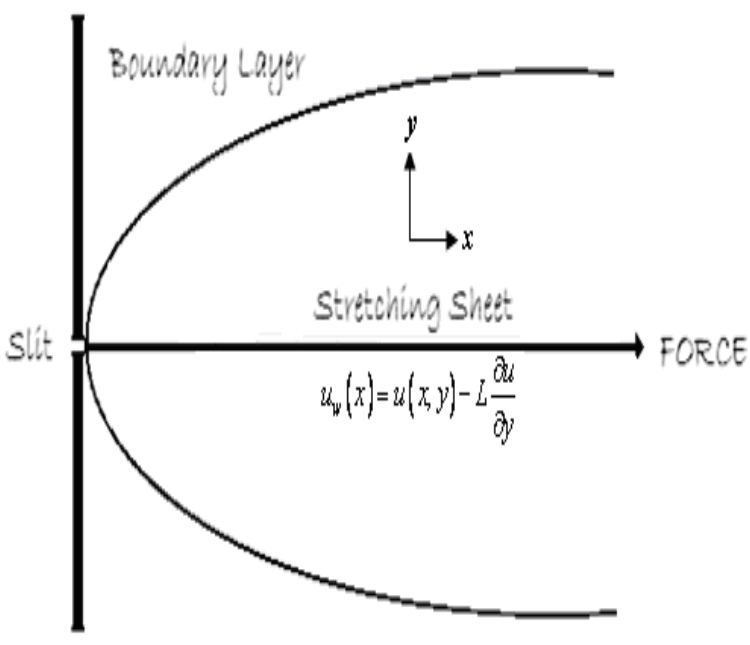

Fig 1 Schematic diagram of stretching sheet

Let us consider the laminar flow of viscous incompressible fluid past a flat and impressible elastic sheet. By applying two equal and opposite forces along the $\mathrm{x}$-axis the sheet is stretched with a speed $u_{w}(x)$ proportional to the distance from the origin $\mathrm{x}=0$. The resulting motion of the otherwise quiescent fluid is caused by the moving sheet, and the flow is governed by steady two-dimensional flow. The viscous fluid is only partially adhering to the stretching sheet. Under the usual boundary layer approximations ,the flow and heat transfer with radiation effects are governed by following equations,

$$
\frac{\partial u}{\partial x}+\frac{\partial v}{\partial y}=0
$$

$u \frac{\partial u}{\partial x}+v \frac{\partial v}{\partial y}=u_{e} \frac{d u_{e}}{d x}+v \frac{\partial^{2} u}{\partial y^{2}}+g \beta\left(T-T_{\infty}\right)-\left(u_{e}-u\right)$

$u \frac{\partial T}{\partial x}+v \frac{\partial T}{\partial y}=\alpha \frac{\partial^{2} T}{\partial y^{2}}-\frac{1}{\rho C_{p}} \frac{\partial q_{r}}{\partial y}+\frac{\mu}{\rho C_{p}}\left(\frac{\partial u}{\partial y}\right)^{2}$

Where $\mathrm{u}$ and $\mathrm{v}$ are the velocities in the $\mathrm{x}$ and $\mathrm{y}$-direction, respectively,$\rho$ is the fluid density, $v$ is the kinametic viscocity , $\mu$ is the dynamic viscocity, $T$ is the temperature, $k$ is the thermal conductivity, $C_{p}$ is specific heat and $q_{r}$ is the radiative heat flux.T he boundary condition given by,

$$
u=u_{w}(x), v=0 \quad T=T_{w}(x) \quad \text { at } \quad y=0
$$

$$
u \rightarrow u_{e}(x) \quad T \rightarrow T_{\infty} \quad \text { as } \quad y \rightarrow \infty
$$

Here

$$
\begin{aligned}
& u_{w}(x)=U_{0} e^{\frac{x}{L}}, \quad u_{e}(x)=U_{s} e^{\frac{x}{L}}, \\
& T_{w}(x)=T_{\infty}+\left(T_{0}+T_{\infty}\right) e^{\frac{2 x}{L}} \\
& q_{r}=-\frac{4 \sigma^{*}}{3 k^{*}} \frac{\partial T^{4}}{\partial y} \quad \text { where } T^{4} \cong 4 T_{\infty}^{3}-3 T_{\infty}^{4} \\
& q_{r}=-\frac{4 \sigma^{*}}{3 k^{*}} 4 T_{\infty}^{3} \frac{\partial T^{4}}{\partial y}=-\frac{16 \sigma^{*} T_{\infty}^{3}}{3 k^{*}} \frac{\partial T}{\partial y}
\end{aligned}
$$

Where $U_{0}, T_{0}$ and $L$ are the reference velocity, temperature and length respectively. The radiative heat flux $q_{r}$ is simplified by Rossnald approximation.

$$
q_{r}=-\frac{4 \sigma^{*}}{3 k^{*}} 4 T_{\infty}^{3} \frac{\partial T^{4}}{\partial y}
$$

The approximation is valid at points optically far from the boundary surface and it is good for intensive absorption, which is for an optically thick boundary layer .It is assumed that the temperature difference with in ye flow such that the term $T^{4}$ may be expressed as linear function of temperature. Hence, expanding $T^{4}$ by Taylor series about $T_{\infty}$ and neglecting higher order terms gives

$$
T^{4} \cong 4 T_{\infty}^{3}-3 T_{\infty}^{4}
$$

The equation (1) is the continuity equation is identically satisfied if we chose the stream fuction $\psi$

Such that,

$$
u=\frac{\partial \psi}{\partial y} \text { and } v=-\frac{\partial \psi}{\partial x}
$$

The momentum and energy equations can be transformed into the corresponding ordinary differential equations by including the following similarity equations, 


$$
\begin{aligned}
\psi & =\sqrt{2 \operatorname{Re}} v e^{\frac{x}{2 L}} f(\eta) \\
T & =T_{\infty}+\left(T_{0}-T_{\infty}\right) e^{\frac{x}{2 L}} \theta(\eta) \\
\eta & =\sqrt{\frac{\operatorname{Re}}{2}} \frac{y}{L} e^{\frac{x}{2 L}}
\end{aligned}
$$

The equations (1)-(5) and are transformed into ordinary differential equation with the aid of equations (8)-(9). Thus the governing equations are,

$$
\begin{aligned}
& f^{\prime \prime}+f f^{\prime \prime}-2 f^{\prime 2}+G r \theta+2 A^{2}=0 \\
& \theta^{\prime \prime}-\frac{\operatorname{Pr}}{1+N r}\left[E c f^{\prime \prime 2}-4 f^{\prime} \theta+f \theta\right]=0
\end{aligned}
$$

Equation (4) and (5) reduces to,

$$
\begin{aligned}
& f^{\prime}(0)=1 \quad, f(0)=0 \quad, \theta(0)=1 \\
& f^{\prime}(\infty) \rightarrow \infty \quad, \theta(\infty) \rightarrow 0
\end{aligned}
$$

Where prime(') denote the differentiation with respect to $\eta$ and dimensionless parameter are:

$$
\begin{aligned}
& G r=\frac{2 g \beta\left(T_{0}-T_{\infty}\right) L}{U_{0}^{\alpha}} \\
& M=\frac{\sigma B_{0}^{2} L}{\rho U_{0}} \\
& A=\frac{U_{s}}{U_{0}} \\
& \operatorname{Pr}=\frac{\mu c_{p}}{k} \\
& \operatorname{Re}=\frac{U_{0} L}{v}
\end{aligned}
$$

parameters viz.Prandtl number Pr, Velocity ratio parameter A,Magnetic parameter M, Grashoff number Gr,Eckert number Ec.The coupled ordinary differential equations (10) \& (11) is third order in $f$ and second order in $\theta$ and which have been reduced to a system of five simultaneous equations for five unknowns. In order to solve numerically this system of equations using Runge-Kutta, we require five initial condion two initial condition in $f$ and one initial condition in $\theta$ are .known. However, the values of $f^{\prime}, \theta$ are known at $\eta \rightarrow \infty$. Thus these condition are utilized to produce to unknown initial condition at $\eta \rightarrow 0$ by using shooting technique.

We discuss two very important matters pertaining to the implementation of the shooting method used for solving the considered boundary layer problem are:

\section{(i)To make decision on the $\infty$ value:}

For making decision on appropriate $\infty$ value for the considered problem depends on the parameters value chosen.In view of this for each parameter combination the appropriate value of $\infty$ has to be decided .For each combination we take a range of values for $\infty$ starting from the $\infty$.If the solution of two successive $\infty$ 's matches to a desired accuracy,then we take this to be the appropriate $\infty$ for given set of parameters.

(ii)To make choice of $f^{\prime \prime}(0), \theta^{\prime}(0)$

The choice of the guess value of unknown initial values of considered boundary value problem can be obtained in a systematic way using qualitative analytical results from the hydromagnetic Newtonian problem for the velocity, temperature and concentration.

\section{NUMERICAL SOLUTION}

In this study, an efficient Runge-Kutta fifth order method along with shooting technique has been employed to analyze the flow of model for the above coupled ordinary differential equations (10) \& (11) for the different values of governing 


\section{RESULTS AND DISCUSSION}

\begin{tabular}{|c|c|c|c|c|c|c|c|}
\hline \multirow{8}{*}{$\mathrm{f}^{\prime \prime}(0)$} & \multirow[t]{2}{*}{ Ec } & \multirow[t]{2}{*}{$\operatorname{Pr}$} & $\mathrm{Gr}$ & \multicolumn{4}{|l|}{ A } \\
\hline & & & & 0.0 & 0.5 & 1.0 & 1.5 \\
\hline & \multirow[t]{3}{*}{0.0} & \multirow[t]{3}{*}{0.5} & 0.0 & -1.281812 & -0.879834 & -0.000000 & 1.220012 \\
\hline & & & 0.5 & -1.077555 & -0.716170 & 0.138387 & 1.341880 \\
\hline & & & 1.0 & -0.895493 & -0.557805 & 0.274749 & 1.462743 \\
\hline & \multirow[t]{3}{*}{0.2} & \multirow[t]{3}{*}{0.5} & 0.0 & -1.281812 & -0.879834 & -0.000000 & -1.220012 \\
\hline & & & 0.5 & -1.075604 & 0.715694 & 0.138391 & 1.342320 \\
\hline & & & 1.0 & -0.892384 & -0.556976 & 0.274774 & 1.463672 \\
\hline \multirow[t]{9}{*}{$\theta^{\prime}(0)$} & \multirow[t]{3}{*}{0.0} & \multirow[t]{3}{*}{0.5} & 0.0 & -1.179958 & -1.339373 & -1.504504 & -1.658153 \\
\hline & & & 0.5 & -1.242363 & -1.362267 & -1.517252 & -1.666519 \\
\hline & & & 1.0 & -1.281362 & -1.383133 & -1.529511 & -1.674727 \\
\hline & \multirow[t]{3}{*}{0.2} & \multirow[t]{3}{*}{0.5} & 0.0 & -1.365553 & -1.322676 & -1.504504 & -1.633826 \\
\hline & & & 0.5 & -1.210547 & -1.349625 & -1.517051 & -1.639012 \\
\hline & & & 1.0 & -1.256733 & -1.373625 & -1.528727 & -1.643802 \\
\hline & \multirow[t]{3}{*}{0.0} & \multirow[t]{3}{*}{1.0} & 0.0 & -1.805700 & -1.946956 & -2.127683 & -2.305635 \\
\hline & & & 0.5 & -1.856859 & -1.967055 & -2.139936 & -2.314040 \\
\hline & & & 1.0 & -1.875391 & -1.985942 & -2.151839 & -3.322307 \\
\hline \multirow[t]{3}{*}{$\theta^{\prime}(0)$} & \multirow[t]{3}{*}{0.2} & \multirow[t]{3}{*}{1.0} & 0.0 & -1.729904 & -1.917009 & -2.127683 & -2.261248 \\
\hline & & & 0.5 & -1.782596 & -1.942764 & -2.139705 & -2.265266 \\
\hline & & & 1.0 & -1.824510 & -1.966317 & -2.150934 & -2.268699 \\
\hline
\end{tabular}

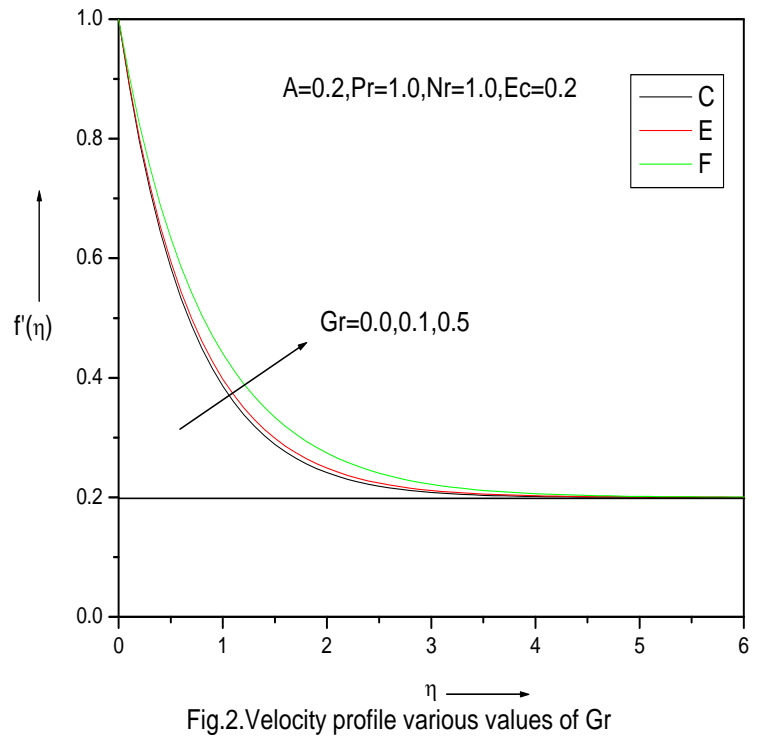

Fig.2.Velocity profile various values of $\mathrm{Gr}$

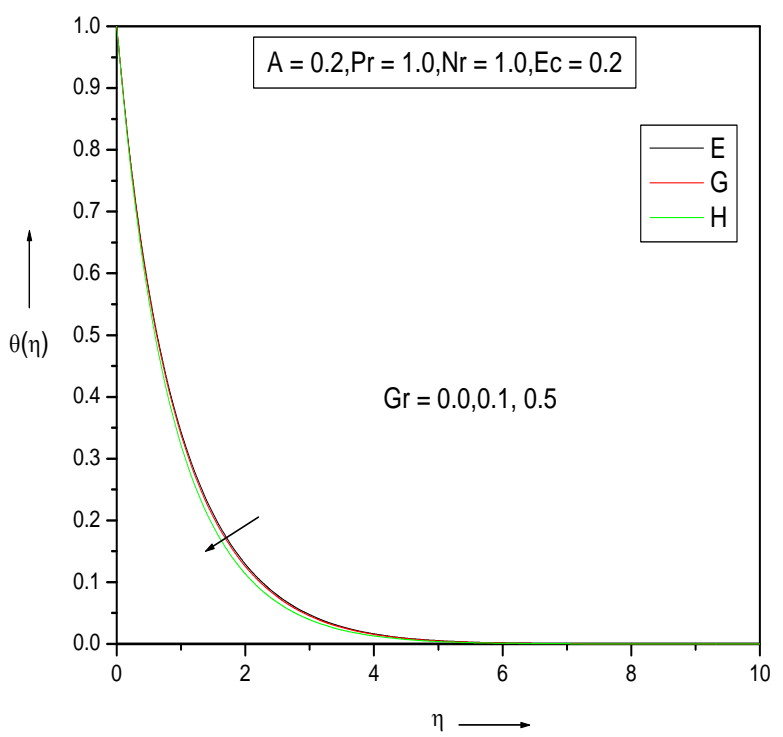

Fig.3.Temperature profile for various values of $\mathrm{Gr}$ 


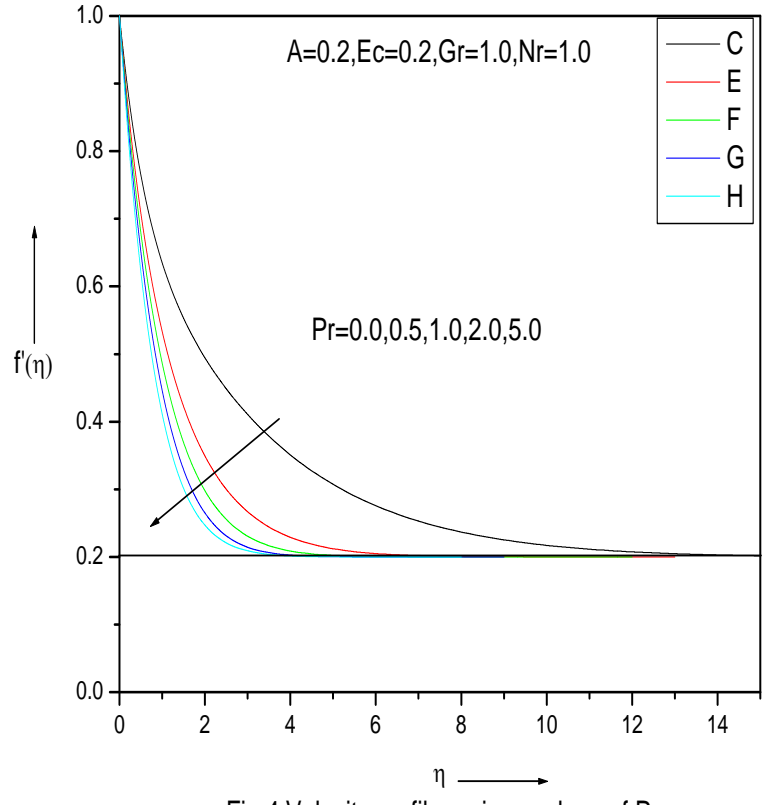

Fig.4.Velocity profile various values of $\mathrm{Pr}$

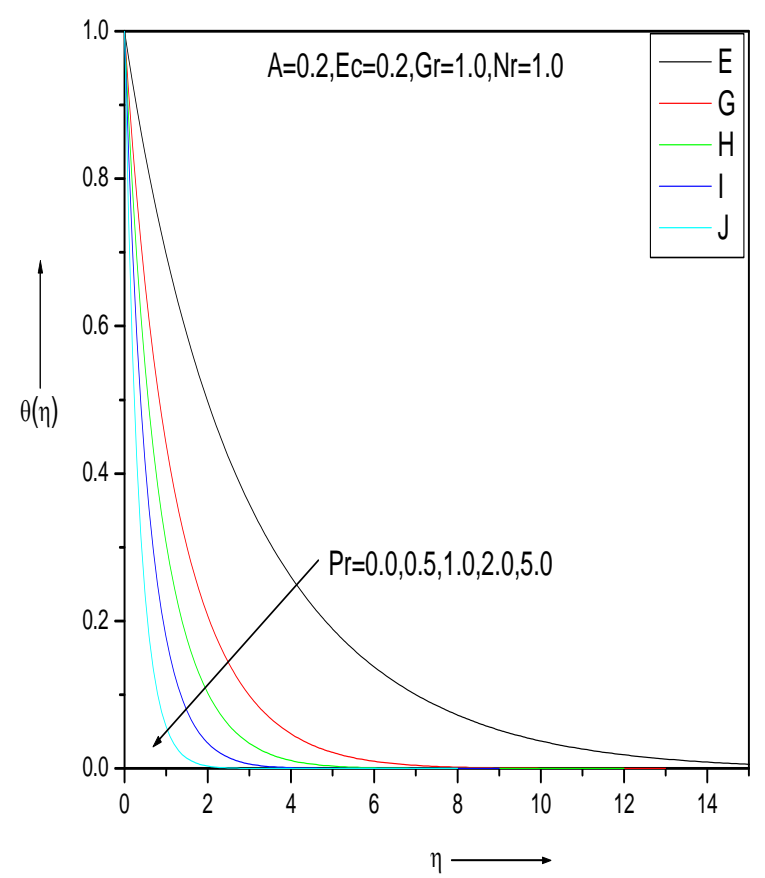

fig.5.Temperature profile various values $\mathrm{Pr}$

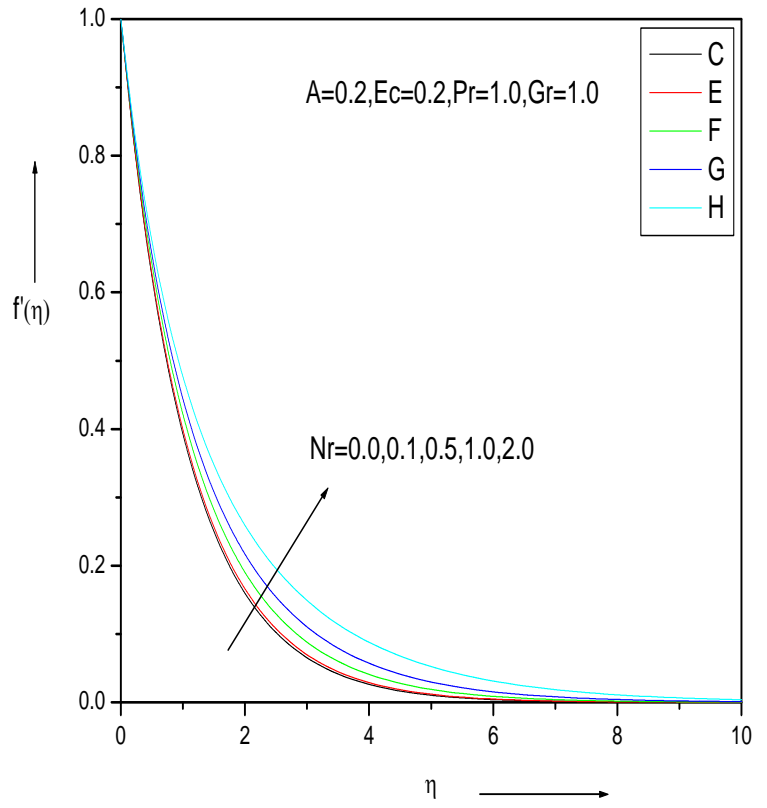

Fig.6.Velocity profile for various values of $\mathrm{Nr}$

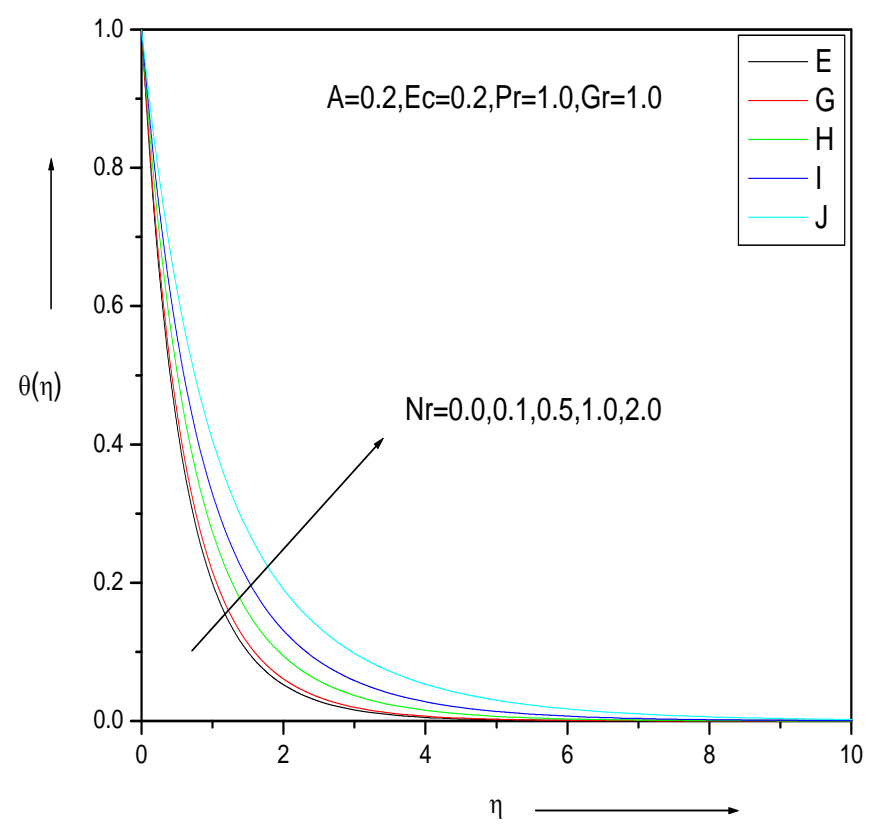

Fig.7.Temperature profile for various values of $\mathrm{Nr}$ 


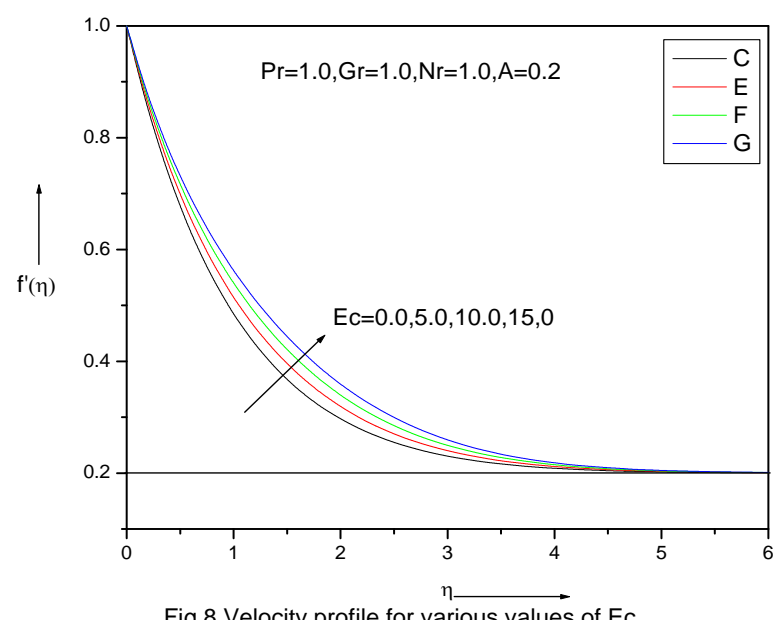

Fig.8.Velocity profile for various values of Ec
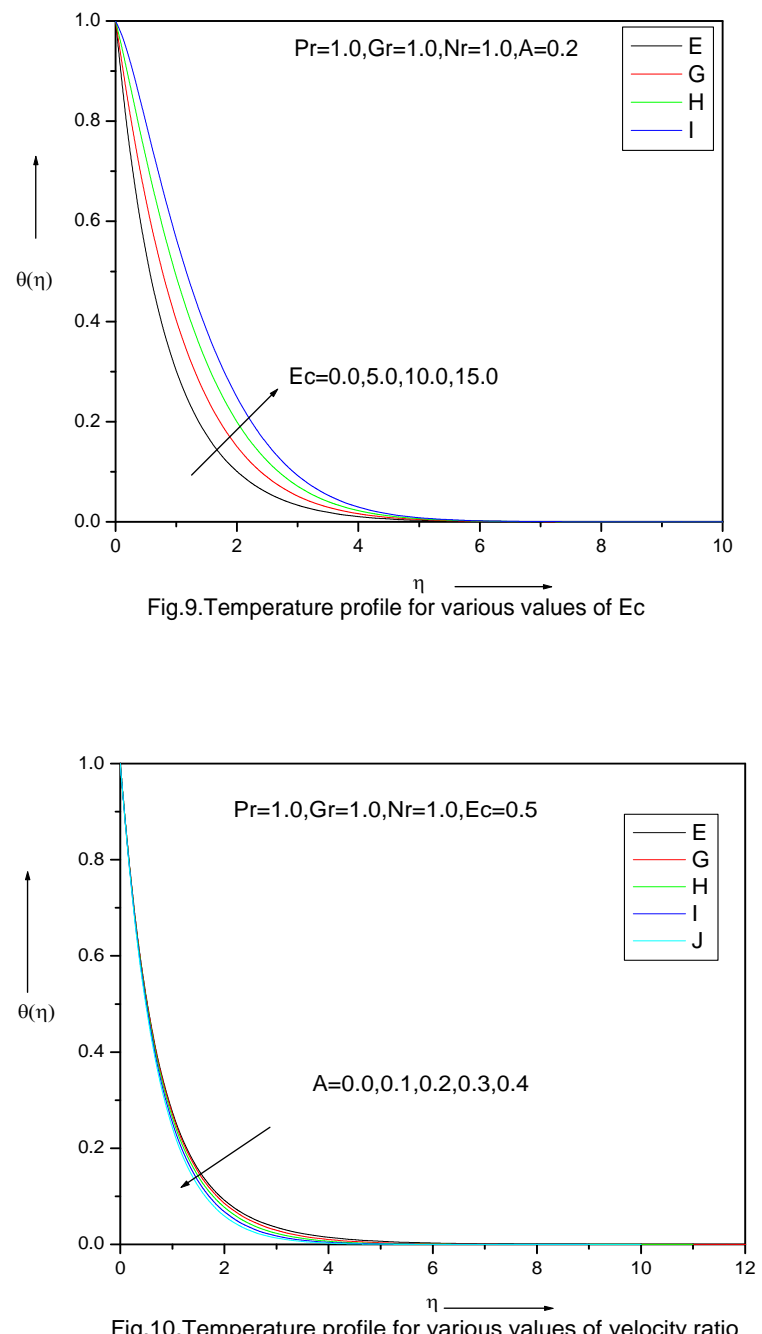

Fig.(7). Illustrates the effect of $\mathrm{Nr}$ in the momentum boundary layer. From this figure it is noticed that the effect of $\mathrm{Nr}$ is to increases the temperature profile also increases, in the momentum boundary layer.

Fig.(8).and Fig.(9).Decipits the effect of Eckert number Ec velocity profile and temperature profile increases values of $\mathrm{Ec}$, increases in thermal boundary layer thickness. In fig $8 \mathrm{Ec}$ converges at 0.2 .

Fig.(2). and Fig.(3).It is noticed that increase in Grashof number leads to increase in velocity and temperature. Further, it is observed that this increase in velocity is due to the velocity difference between stretched wall and the surrounding fluid. Grashof number leads to increase in velocity decreases and decays the velocity at 0.2 , Gr leads to increase in the boundary layer thickness.

Fig. (4) and Fig. (5) Represents the effect of Prandtl number $\operatorname{Pr}$ on the heat transfer, From these plots it is evident that large values of Prandtl number results in decrease in temperature and Velocity of the flow field. Since it is well known that the thermal boundary layer thickness is inversely proportional to the square root of Prandtl number, the decrease of temperature profile with Pr is straight forward in both cases.

Fig.(6). Depicts the effect of parameter $\mathrm{Nr}$ over velocity profile, and it is noticed from this figure that the velocity increases with the increase in parameter $\mathrm{Nr}$, which offers resistance to the flow resulting in decrease of velocity in the boundary layer. which concurs with the results of various authors.

Fig.(10).represent the variation of temperature graph with Prandtl number Pr. The graph decipits that temperature decreases. This is due to the fact that a higher Prandtl number fluids has relatively low thermal conductivity, which es reduces conduction and there by the thermal boundary layer thickness and as a result, temperature decreases.

\section{CONCLUSIONS}

In this paper ,the momentum boundary layers over a stretching surface with variable thickness were investigated. The effect of velocity ratio MHD Boundary Layer Stagnation Point Flow Over an exponentially stretching sheet was investigated the numerical results obtained agreed very well with previously reported case available in the literature The velocity ratio diminishes along the temperature gradiant. 


\section{LIST OF SYMBOLS}

a Parameter of temperature distribution on the stretching surface

$B_{0} \quad$ Externally imposed magnetic field in the $y$-direction

(T)

$C_{b} \quad$ Drag coefficient

$C_{f} \quad$ Local skin-friction coefficient

$c_{p} \quad$ Specific heat of the fluid at constant pressure $(\mathrm{J} / \mathrm{kg} \mathrm{K})$

Ec Eckert number

$f \quad$ Dimensionless stream function

$g \quad$ Acceleration due to gravity $\left(\mathrm{m} / \mathrm{s}^{2}\right)$

Gr Grashof number

Ha Hartmann number

$k$ Permeability $\left(\mathrm{m}^{2}\right)$

$L \quad$ Characteristic length (m)

$\mathrm{Nu}_{x} \quad$ Nusselt number

Pr Prandtl number

$Q \quad$ Internal heat generation/absorption coefficient $\left(\mathrm{W} / \mathrm{m}^{3}\right.$

K)

$q \quad$ Local surface heat flux $\left(\mathrm{W} / \mathrm{m}^{2}\right)$

$\mathrm{Re}_{x} \quad$ Local Reynolds number

$T \quad$ Fluid temperature (K)

$T_{\infty} \quad$ Ambient temperature (K)

$T_{0} \quad$ Reference temperature (K)

$T_{w} \quad$ Wall temperature (K)

$u \quad$ Fluid axial velocity $(\mathrm{m} / \mathrm{s})$

$U_{0} \quad$ Reference velocity $(\mathrm{m} / \mathrm{s})$

$U_{w} \quad$ Velocity of vertical stretching surface $(\mathrm{m} / \mathrm{s})$

$v \quad$ Fluid transverse velocity $(\mathrm{m} / \mathrm{s})$

$x, y$ Coordinates along and normal to the vertical stretching surface plate $(\mathrm{m})$

$X \quad$ Dimensionless coordinate along the plate

$v \quad$ Kinematic viscosity $\left(\mathrm{m}^{2} / \mathrm{s}\right)$

$\tau_{w x} \quad$ Local shear stress $(\mathrm{Pa})$

$\alpha \quad$ Thermal diffusivity $\left(\mathrm{m}^{2} / \mathrm{s}\right)$

$\beta \quad$ Coefficient of thermal expansion (1/K)

$\eta \quad$ Non-dimensional transformed variable

$\lambda$ Dimensionless heat generation /absorption parameter

$\mu \quad$ Viscosity of the fluid (Pa s)

$\sigma \quad$ Fluid electrical conductivity ( $/ \mathrm{m})$

$\psi \quad$ Stream function $\left(\mathrm{m}^{2} / \mathrm{s}\right)$

$\rho \quad$ Fluid density $\left(\mathrm{kg} / \mathrm{m}^{3}\right)$

$\theta \quad$ Dimensionless temperature

\section{Subscripts}

$x \quad$ Local

$w \quad$ Conditions on the wall

0 Reference

$\infty \quad$ Ambient or free stream condition

\section{REFERENCES}

[1]. A.Ishak, MHD boundary layer flow due to an exponentially stretching sheet with radiation effect,Sains Malaysiana, 40(2011), 391-395.

[2]. A.Raptis, C. Perdikkis and H.S. Takhar, Effect of Thermal Radiation on MHD Flow, Int. J. Heat Mass Transfer, 153(2004), 645-649.

[3]. B.Bidin and R. Nazar, Numerical solution of the boundary layer flow over an exponentially stretching sheet with thermal radiation, European journal of scientific research, 33(2009), 710-717.

[4]. B.C. Sakiadis, Boundary-layer behaviour on continuous solid surfaces: I. Boundary-laye equations for twodimensional and axi-symmetric flow,Am Inst Chem Eng Journal, 7(1961), 26-28.

[5]. B.K. Dutta, P. Roy and A.S. Gupta, Temperature field in flow over a stretching surface with uniform heat flux, Int. Comm. Heat Mass Transfer. 12(1985), 89-94.

[6]. E.M. Aboeldahab and M.S. EI Gendy, Radiation effect on MHD free convective flow of a gas past a semi-infinite vertical plate with variable thermo physical properties for high-temperature difference, Can. J. Phys.,80(2002), 16091619.

[7]. E. Magyari and B. Keller, Heat and transfer in the boundary layers on an exponentially stretching continuous surface, J. Phys. D: Appl.Phys,32(1999), 577-585.

[8]. L.J. Crane, Flow past a stretching sheet, Z. Angew. Math. Phys, 21(1970), 645-647.

[9]. M.K. Partha, P.V.S.N. Murthy and G.P. Rajasekhar, Effect of viscousdissipation on the mixed convection heat transfer from an exponentiallystretching surface, Heat Mass Transfer, 41(2005), 360-366.

[10]. M. Sajid and T. Hayat, Influence of thermal radiation on the boundary layer flow due to an exponentially stretching sheet, Int. Comm. Heat Mass Transfer, 35(2008), 347-356.

[11]. P. Carragher and L.J. Crane, Heat transfer on a continuous stretching sheet, Z. Angew. Math. Mech., 62(1982), 564-573.

[12]. P.S. Gupta and A.S. Gupta, Heat and mass transfer on stretching sheet with suction or blowing, Can. J. Chem. Eng., 55(1977), 744-746.

[13]. R.N. Jat and S. Chaudhary, Magnetohydrodynamic boundary layer flow near the stagnation point of a stretching sheet, IL NUOVO CIMENTO,123(2008), 555-566.

[14]. R.N. Jat and S. Chaudhary, MHD flow and heat transfer over a stretching sheet, Applied Mathematical Science, 3(2009), 1285-1294. 
[15]. R.N. Jat, S. Chaudhary, Unsteady magnetohydrodynamic boundary layer flow over a stretching surface with viscous dissipation and joule heating,IL NUOVO CIMENTO, 124(2009), 53-59.

[16]. R.N. Jat and S. Chaudhary, Radiation effects on the MHD flow near the stagnation point of a stretching sheet. Z. Angew. Math. Phys., 61(2010),1151-1154.

[17]. S. Rosseland, Theoretical Astrophysics. New York: Oxford University,(1936).

[18]. Sakiadis, B.C. 1961. "Boundary-layer Behavior on Continuous Solid Surfaces: I Boundary Layer Equations for Two Dimensional and Ax4mmetric Flow", AIChE J7, pp. 26-28.

[19]. Cortell, R. 2006. Effects of viscous dissipation and work done by deformation on the MHD flow and heat transfer of a viscoelastic fluid oever a stretching sheet. Physics Letters A 357: 298-305.

[20]. D.Pal,S.Chatterjee,Heat and transfer in MHD nonDarcian flow of a micropolar fluid over a stretching sheet embedded in a porous media with non-uniform heat source and thermal radiation ,commun. Nonlinear Sci.Number.Simul.15 (2010) 1843-1857

[21]. A.Ahmed,Similarity solution in MHD :effects of thermal diffusion and diffusion thermo on free convective heat and mass transfer over a stretching surface considering suction or injection ,Commun.Nonlinear Sci.NUmer.Simul.14 (2009) 2202-2214.

[22]E.M.Abo-Eldahab,connective heat transfer,by the presence of radiation in an electrically conducting fluid at a stretching surface .Can.J.Phys. 79 (2001) 929-937.

[23]. D.Pal,Heat and mass transfer in stagnation -point flow towards a stretching surface in the presence of buoyancy force and thermal radiation ,Meccanica 44 (2009) 145-158. 